\title{
Behandling av skafoidfrakturar i eit lokalsjukehus
}

BAKGRUNN Skafoidfraktur er vanleg og kan lett bli oversett klinisk. Målet med denne studien var å finne førekomsten av denne skaden og behandlingsresultatet for pasientar med skafoidfraktur ved vår avdeling.

MATERIALE OG METODAR Alle pasientar med skafoidfraktur som var behandla ved Ortopedisk seksjon, Haugesund sjukehus, frå 1987 og til og med 2011 blei inkluderte. Data blei samla inn ved journalgjennomgang.

RESULTAT 415 pasientar blei inkluderte. 302 (73\%) var menn, og gjennomsnittsalderen var 35 år. Sluttresultatet er kjent for 385 pasientar (93\%), og berre desse er inkluderte i resultatanalysen. Immobilisering med gips hos 308 gav røntgenologisk lækjing hos 281 (91\%), og etter 26 operasjonar var brotet til slutt lækt hos 302 (98\%). 17 pasientar fekk primært behandling med operasjon av di det var stor feilstilling. Etter maksimalt to reoperasjonar var alle brota lækt. Av totalt 325 pasientar som fekk adekvat primærbehandling var brotet lækt hos 319 (98\%). 60 pasientar gjekk lang tid utan behandling. Etter først gipsing og så 38 operasjonar lækte frakturen hos 41 (68\%). Totalt blei det hos 66 pasientar (17\%) påvist pseudartrose. 50 av 66 pseudartrosepasientar blei opererte, hos $84 \%$ av dei blei brotet lækt. Til slutt var det lækt hos 360 av 385 pasientar (93\%). 25 pasientar (7\%) fekk persisterande pseudartrose.

TOLKING Resultatet av gipsing og operasjon var tilfredsstillande. Adekvat primærbehandling av skafoidfrakturar gir god prognose, men mange blir først oppdaga seint i forløpet.

Skafoidfraktur i handleddet er ein vanleg tilstand og utan samanlikning den vanlegaste frakturen i handrotsbeina (1). Årsaken er nesten alltid eit fall på utstrekt arm med dorsalfleksjon og radialdeviasjon i handleddet (fig 1). Problemet er sein tilheling pga. dårleg blodforsyning og fare for avaskulær nekrose.

Frakturen har også alle grader av dislokasjon. Det er ofte lite smerter, slik at skaden kan bli oversett. Brotet kan vere vanskeleg å oppdage på røntgen, og skråbilder kan vere nødvendig. Dersom ein etter vanleg røntgenundersøking er usikker, kan ein komplettere med CT- eller MR-undersøking. Ved usikker diagnose er det også vanleg rutine å ta nytt røntgenbilde etter om lag ti dagar. Behandlinga er primært immobilisering med gips, men brotet kan ta lang tid å lækje pga. dårleg blodforsyning (2). Operasjon kan vere indisert når det er relativt stor dislokasjon, forseinka lækjing eller pseudartrose, noko om lag 5-10\% av desse pasientane får (3-5). Dislokasjon $>1 \mathrm{~mm}$ er vanlegvis operasjonsindikasjon. Ved manglande røntgenologisk lækjing etter 4-6 månader med gips bør ein også vurdere operasjon (6).

Operativ behandling inneber skruefiksering, beintransplantasjon eller begge delar, i tillegg til gipsing (7). Pinning blir også brukt. Mistanke om perilunar instabilitet styrker operasjonsindikasjonen (8). Primær operativ behandling med skruefiksering av udisloserte eller minimalt disloserte brot er også forsøkt, men blir ikkje tilrådd som rutine $(2,9,10)$. Operasjonen kan gjerast med open eller med kombinert perkutan og artroskopisk teknikk. Udisloserte frakturar kan opererast med berre perkutan skruefiksering. Vaskularisert transplantat fra radius er også brukt for pseudartrose (11).

Målet med denne studien var å kartlegge forekomsten av skafoidfraktur generelt og behandlinga av denne tilstanden ved avdelinga, som eit ledd i kvalitetssikringsarbeidet.

\section{Materiale og metode}

Alle pasientar med skafoidfraktur som blei behandla ved Ortopedisk seksjon, Haugesund sjukehus, frå 1987 og til og med 2011 blei inkluderte. Data blei samla ved journalgjennomgang etter diagnosekode. Innsamla data er brukt til å setje saman ein eigen database, som er klarert av personvernombudet. Delar av materialet er publisert tidlegare (12). Data er analyserte ved bruk av Statistica for Windows, Release10 B (Stat Soft Inc., Tulsa, OK).

\section{Resultat}

415 pasientar med skafoidfraktur blei inkluderte. 302 (73\%) var menn. Gjennomsnittsalderen ved skadetidspunktet var 35 år (spreiing 9,5-97,4 år) og lågare for menn enn for kvinner (30,8 år mot 46,3 år). $48 \%$ hadde fraktur på høgre side. Skademekanismen er kjent for 410 pasientar. $345(84 \%)$ av dei hadde hatt eit fall. 65 pasientar hadde hatt forskjellige former for klemskade eller vært i trafikkulukker. Sju pasientar hadde annan handrotsfraktur i tillegg - 16 radius-

\section{Birger Valen}

birger.valen@getmail.no

Ortopedisk seksjon

Haugesund sjukehus

ID Eng Engelsk omsetjing på www.tidsskriftet.no

\section{HOVUDBODSKAP}

Skafoidfrakturar blir ofte oversette klinisk

Rask primærbehandling med gips eller operasjon gav lækjing hos $98 \%$

$A v$ dei som blei opererte for seinare pseudartrose, blei $84 \%$ lækt 


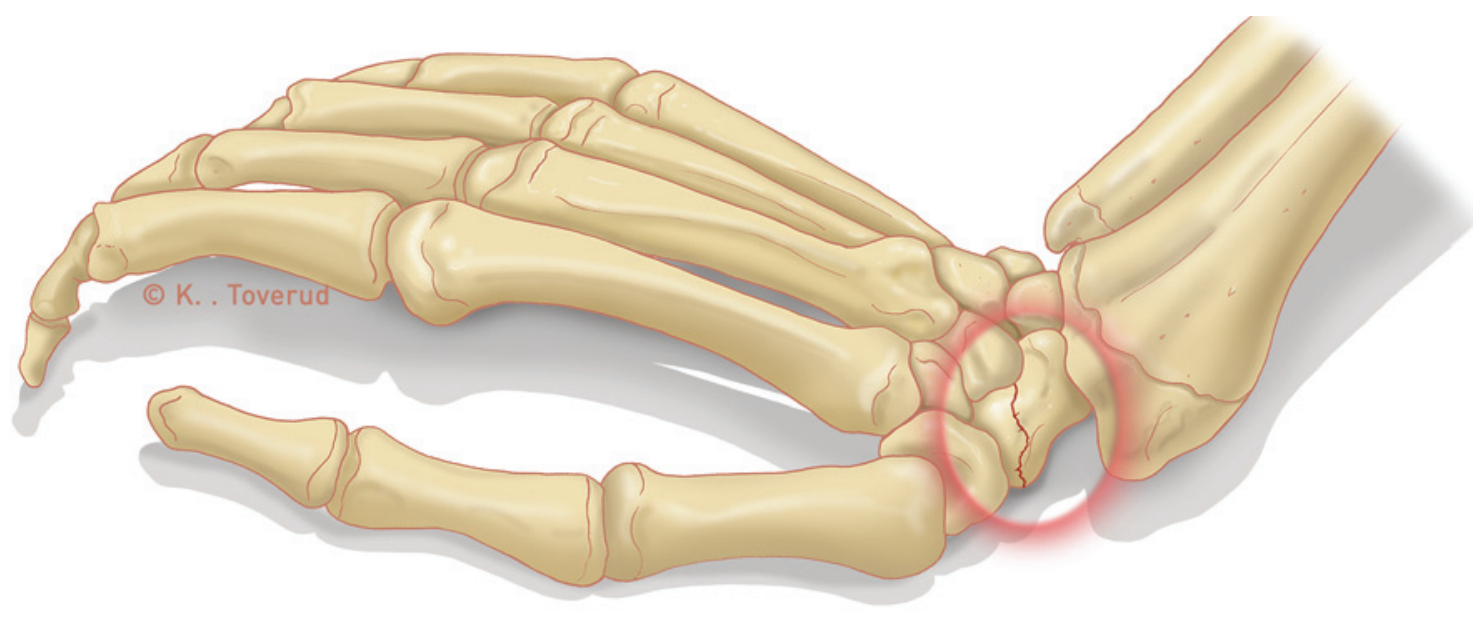

Figur 1 Den vanlegaste skademekanismen ved skafoidfraktur

fraktur og tre metakarpfraktur. Tre hadde lunatumluksasjon. 336 (81\%) fekk primærbehandling med gipsing inklusive tommelfingerens grunnfalang. $18(4 \%)$ blei opererte innan eitt døgn av di det var for stor feilstilling. Som primær operasjonsmetode blei det brukt open reponering og skruefiksering med Herbert-skrue. Ved røntgenologisk påvist manglande lækjing eller pseudartrose blei det i tillegg gjort beintransplantasjon med kortikospongiøs protese og gipsing i minst to månader. Operasjonane vart gjort både fra dorsalsida og volarsida ut frå operatørpreferanse.

61 pasientar (15\%) gjekk lenge med ubehandla fraktur - fra fleire månader til eitt år - anten av di pasienten sjølve ignorerte skaden eller av di skaden i første omgang blei feilvurdert av primærkontakten. På grunn av vedvarande smerter $\mathrm{i}$ handleddet blei det så tatt røntgenbilde, som viste fraktur.

30 pasientar er kontrollerte ved andre norske eller ved utanlandske sjukehus. Vi har informasjon om sluttresultatet for 385 pasientar (93\%), mellom dei 77 opererte. Berre desse 385 pasientane med kjent sluttresultat er med i den påfølgande resultatanalysen (fig 2).

Primær immobilisering med gips hos 308 pasientar gav tilfredsstillande røntgenologisk lækjing hos 281 (91\%). 27 fekk påvist manglande lækjing eller pseudartrose. Tre avslo meir behandling. 24 blei opererte og det blei påvist lækt brot hos 20. To av dei resterande fire blei reopererte, med lækjing hos ein. Sluttresultatet i denne gruppa blei lækjing hos 302 av 308 (98\%), mens seks ( $2 \%)$ hadde persisterande pseudartrose.

17 fekk operasjon som primærbehandling av di feilstillinga var for stor, og hos 15 $(88 \%)$ vart brotet lækt. Dei to gjenverande blei vellukka reopererte - slik at alle i denne gruppa til slutt vart lækte.

60 pasientar gjekk lenge utan behandling (frå ein månad til fleire år), 24 pasientar med relativt kort forseinking ( $>3 \mathrm{md}$.) fekk gips og 11 vart lækt. 13 av dei resterande 49 avslo vidare behandling og 36 blei opererte, med lækjing hos 28 . To blei vellukka reopererte, slik at sluttresultatet blei lækjing hos 41 av $60(68 \%)$ i denne gruppa. 19 pasientar (32\%) utvikla persisterande pseudartrose.

Totalt fekk 66 pasientar (17\%) påvist pseudartrose, noko som var assosiert med forseinka immobilisering $(75,0 \%$ versus $6,5 \%$ ). 50 pasientar med pseudartrose blei opererte, av desse blei 39 (78\%) lækt etter første operasjon - $42(84 \%)$ etter reoperasjonar. 42 av pasientane med pseudartrose (63\%) blei lækt til slutt. 41 av 325 pasientar (13\%) med adekvat behandling og 36 av dei 60 som fekk forseinka primærbehandling $(60 \%)$ blei vurdert til å trenge operasjon. Til saman 77 pasientar blei opererte, 17 av dei som primærbehandling. Ti blei opererte for manglande lækjing og 50 for pseudartrose etter gjennomsnittleg 23 månader. Hos dei 77 som blei opererte blei det påvist tilfredsstillande lækjing hos 63 (82\%) etter første operasjonen og hos $68(88 \%)$ etter seks reoperasjonar. Det var ingen forskjell i lækjingsfrekvens mellom operasjonane for feilstilling, for forseinka lækjing eller for pseudartrose.

Seks pasientar blei først opererte for feilstilling, manglande lækjing eller pseudartrose og deretter reopererte med ny beintransplantasjon og fiksasjon etter gjennomsnittleg 15,3 månader. Fem av dei blei lækt.

Totalt blei brotet lækt hos 360 av 385 (93\%). Dei resterande 25 pasientane $(7 \%)$ med symptomfri eller nesten symptomfri pseudartrose avslo vidare behandling. 19 kom fra gruppa med forseinka primærbehandling.

\section{Diskusjon}

Alders- og kjønnsfordeling i dette materialet er om lag som $i$ andre materiale $(4,13,14)$. Vi hadde berre ein pasient som var under ti år. Dette samsvarer med at skafoidfrakturar er relativt sjeldan hos barn (15-17). $15 \%$ av pasientane våre gjekk lenge med ubehandla fraktur - dette samsvarer med at skafoidfrakturar ofte blir oversette sidan det er lite symptom og lite kliniske funn (18). Diagnosen er ofte usikker, og berre om lag ein tredel av pasientane der det var klinisk mistanke om skafoidfraktur hadde sikker fraktur. Også dette samsvarer om lag med andre rapportar (19). Tidleg kontroll med spesialbilde eller MR-undersøking (19) er derfor ofte nødvendig, og vil i fleirtalet av tilfelle avkrefte mistanken eller påvise fraktur i andre handrotsbein $(6,16,18)$.

Det årlege talet på pasientar steig i inklusjonsperioden (data ikkje vist), noko som kan skuldas at innføring av MR-undersøking på sjukehuset vårt frå 2002 har ført til at brot som ikkje ville blitt oppdaga på vanleg røntgenundersøking nå blir registrert. Opptaksomådet for sjukehuset har også blitt utvida i inklusjonsperioden. Vår rutinebehandling for udislokerte frakturar inneber gipsing av tommelfingerens grunnledd. Om det er nødvendig å gipse inn tommelens grunnledd er omdiskutert $(14,19)$. Ifølgje fleire studiar kan ein gipse som ved vanleg radiusfraktur $(14,20,21)$. Tida med gips vil vere avhengig av både røntgenbilder og kliniske funn (6). At slik gipsing gir lækjing hos om lag $90 \%$ av pasientane, slik som i vårt materiale, samsvarer med andre rappor$\operatorname{tar}(6,9)$. Vi har ikkje brukt operasjon for udislokerte frakturar, slik enkelte tilrår (22). Om det er indikasjon for å operere udislokerte skafoifrakturar er eit kontroversielt spørsmål $(2,23)$.

Vi har berre brukt reponering og skruefiksering som primærbehandling ved disloserte brudd ( $>1 \mathrm{~mm}$ diastase), og da med gipsing i tillegg. Skruefiksering kan også bli gjort med perkutan teknikk (10) eller med ein kombinasjon av perkutan og endoskopisk teknikk (24). Operasjon kan bli gjort frå både volar- og dorsalsida (25). Operasjon frå volarsida er teoretisk meir skånsom for blodforsyninga, mens operasjon på dorsal- 


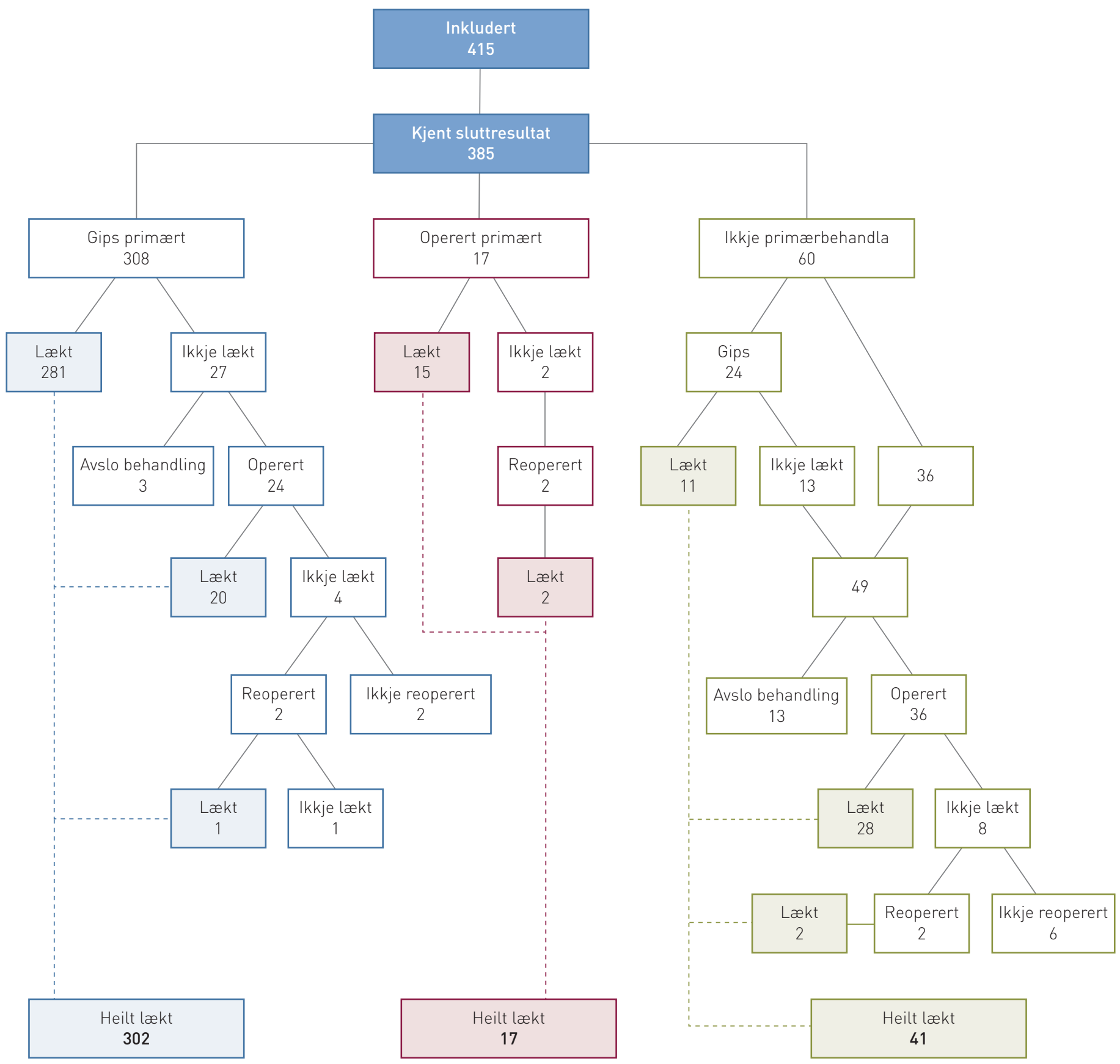

Figur 2 Gangen i behandlinga hos dei 385 pasientane med kjent sluttresultat

sida gir betre tilgang (25). Ingen forskjell i sluttresultat er dokumentert (25). At for sein (over ein månad forseinking) immobilisering fører til auka forekomst av pseudartroseutvikling, slik det gjer i vårt materiale, samsvarer med andre studiar $(6,7,18,26)$. At om lag $90 \%$ av pseudartroseoperasjonar gir lækjing, samsvarer med ein annan studie (27). Om lag $12 \%$ av pasientane våre måtte ha operasjon, enkelte også reoperasjon, pga. pseudartrose. Dette samsvarer også med andre rapportar $(3,4)$. Ekstra kontroll etter seks månader blir tilrådd for å oppdage og behandle pseudartrose tidleg (3).

Beintransplantasjon med og utan skruefiksering er hovudmetoden ved operativ behandling for pseudartrose (3). Vi har ingen erfaring med vaskulariserte beintransplantat, noko som har gitt gode resultat (11). Enkelte meiner at asymptomatiske og tilfeldig oppdaga navikularepseudartroser kan vere ubehandla (16), andre tilrår operasjon av symptomfrie pseudartroser for å hindre utvikling av radiokarpalartrose $(3,6)$. Når det gjeld denne tilstanden, er det ofte lite samsvar mellom røntgenbilde og kliniske funn (4).

\section{Birger Valen (f. 1946)}

er spesialist i ortopedisk kirurgi.

Forfattaren har fylt ut ICMJE-skjemaet og oppgjev ingen interessekonfliktar.
Litteratur

1. Papp S. Carpal bone fractures. Orthop Clin North Am 2007; 38: 251-60, vii.

2. Vinnars B, Pietreanu M, Bodestedt A et al. Nonoperative compared with operative treatment of acute scaphoid fractures. A randomized clinical trial. J Bone Joint Surg Am 2008; 90: 1176-85.

3. Prosser GH, Isbister ES. The presentation of scaphoid non-union. Injury 2003; 34: 65-7.

4. Düppe $H$, Johnell $O$, Lundborg $G$ et al. Long-term results of fracture of the scaphoid. A follow-up study of more than thirty years. J Bone Joint Surg Am 1994; 76: 249-52.

5. Ring D, Jupiter JB, Herndon JH. Acute fractures of the scaphoid. J Am Acad Orthop Surg 2000; 8 : 225-31.

6. Thorleifsson R, Karlsson J, Sigurjonsson K. Fractures of the scaphoid bone. A follow-up study. Arch Orthop Trauma Surg 1984: 103: 96-9.

7. Phillips TG, Reibach AM, Slomiany WP. Diagnosis and management of scaphoid fractures. Am Fam Physician 2004; 70: 879-84 
8. Durand S, MacQuillan A, Delpit X. Isolated scaphoid fracture with anterosuperior dislocation of the proximal fragment. Chir Main 2011; 30: 298-301.

9. Saedén B, Törnkvist H, Ponzer S et al. Fracture of the carpal scaphoid. A prospective, randomised 12-year follow-up comparing operative and conservative treatment. J Bone Joint Surg Br 2001; 83: $230-4$.

10. Bond CD, Shin AY, McBride MT et al. Percutaneous screw fixation od cast immobilization for nondisplaced scaphoid fractures. J Bone Joint Surg Am 2001; 83-A: 483-8.

11. Zaidemberg C, Siebert JW, Angrigiani C. A new vascularized bone graft for scaphoid nonunion. J Hand Surg Am 1991; 16: 474-8.

12. Valen B. Behandling av fraktur i handrota. Tidsskr Nor Legeforen 2009; 129: 183-5.

13. Hove LM. Epidemiology of scaphoid fractures in Bergen, Norway. Scand J Plast Reconstr Surg Hand Surg 1999; 33: 423-6.

14. Schubert HE. Scaphoid fracture. Review of diagnostic tests and treatment. Can Fam Physician 2000; 46: 1825-32.

15. Christodoulou AG, Colton CL. Scaphoid fractures in children. J Pediatr Orthop 1986; 6: 37-9.
16. Amadio PC, Taleisnik J. Fractures of the carpal bones. I: Green DP. Operative hand surgery. Bd. I. New York: Churchill Livingstone, 1993.

17. Gutierrez G. Office management of scaphoid frac tures. Phys Sportsmed 1996: 24: 60-70.

18. Roolker W, Maas M, Broekhuizen AH. Diagnosis and treatment of scaphoid fractures, can nonunion be prevented? Arch Orthop Trauma Surg 1999; 119: 428-31.

19. Furunes H, Vandvik PO. Gips ved mistanke om skafoidfraktur. Tidsskr Nor Legeforen 2009; 129: 177-9.

20. Clay NR, Dias JJ, Costigan PS et al. Need the thumb be immobilised in scaphoid fractures? A randomised prospective trial. J Bone Joint Surg Br 1991; 73: 828-32.

21. Doornberg JN, Buijze GA, Ham SJ et al. Nonoperative treatment for acute scaphoid fractures: a systematic review and meta-analysis of randomized controlled trials. J Trauma 2011; 71: 1073-81.

22. Arora R, Gschwentner M, Krappinger D et al. Fixation of nondisplaced scaphoid fractures: making treatment cost effective. Prospective controlled trial. Arch Orthop Trauma Surg 2007; 127: 39-46.

23. Buijze GA, Doornberg JN, Ham JS et al. Surgical compared with conservative treatment for acute nondisplaced or minimally displaced scaphoid fractures: a systematic review and meta-analysis of randomized controlled trials. J Bone Joint Surg Am 2010; 92: 1534-44.

24. Slade JF 3rd, Gutow AP, Geissler WB. Percutaneous internal fixation of scaphoid fractures via an arthroscopically assisted dorsal approach. J Bone Joint Surg Am 2002; 84-A (suppl 2): 21-36.

25. Polsky MB, Kozin SH, Porter ST et al. Scaphoid fractures: dorsal versus volar approach. Orthopedics 2002; 25: 817-9.

26. Langhoff $\mathrm{O}$, Andersen JL. Consequences of late immobilization of scaphoid fractures. J Hand Surg [Br] 1988; 13: 77-9.

27. Inoue G, Shionoya K, Kuwahata Y. Herbert screw fixation for scaphoid nonunions. An analysis of factors influencing outcome. Clin Orthop Relat Res 1997; 343: 99-106.

Mottatt 9.2. 2012, første revisjon innsendt 17.7. 2012, godkjent 21.3. 2013. Medisinsk redaktør Are Brean. 